Military Technical College Kobry El-Kobbah, Cairo, Egypt

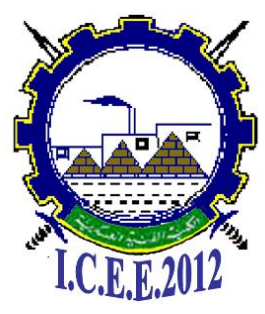

$6^{\text {th }}$ International Conference

on

Chemical \& Environmental

Engineering

29 - 31 May, 2012

CEEA-2

\title{
CONTRIBUTION OF ELECTROMAGNETIC FIELD IN ELIMINATION OF A HEAVY METAL FROM INDUSTRIAL WASTEWATER
}

\author{
Olfat A. Fadali*, Ebrahiem E. Ebrahiem*, Mohamed S. Mahmoud* and Mohamed Obaid*
}

\begin{abstract}
The role of electromagnetic field (EMF) in enhancement of copper (II) removal from industrial wastewater effluent has been investigated. The rate of copper (II) removal from industrial wastewater by cementation on rotating iron cylinder subjected to a magnetic field was studied to demonstrate the effect of EMF on the rate of cementation. The results proved the enhancement of copper removal by utilization of EMF; however the effect of decreasing the thickness of boundary layer is more dominant than the effect of EMF. The rate of mass transfer was correlated by the equation $\mathrm{sh}=2.3 \mathrm{Re}^{0.95} \mathrm{Sc}^{0.33}$. Another correlation provides the relation between mass transfer coefficient and the other operating variables namely: intensity of EMF, initial copper concentration and rotation speed of iron cylinder $\mathrm{k}=\exp \left(1.4 * 10^{-3} * \mathrm{~N}+1.2 * 10^{-3} * \mathrm{C}_{0}+4.1 * 10^{-4} * \mathrm{H}-0.5\right)$. This work illustrates that the enhancement of copper recovery in presence of EMF is due to the induced motion of paramagnetic $\mathrm{Fe}^{+\mathrm{n}}$ in the solution and is limited in the range of cylinder rotation speed of 300 900 rpm. It was evident that power consumption due to utilization of magnetic field is less by $3 \%$ than that without utilization of EMF.
\end{abstract}

Keywords: Cementation, Electromagnetic Field, Copper Ions, rotating cylinder.

* Chemical Engineering Department, Faculty of Engineering, Minia University, Minia, Egypt, Email: msmm122@yahoo.com 


\section{Introduction}

Industrial use of metals and other domestic processes have introduced substantial amounts of potentially toxic heavy metals into the atmosphere and into the aquatic and terrestrial environments. Discharged toxic metals typically include $\mathrm{Cd}, \mathrm{Cu}, \mathrm{Ni}, \mathrm{Cr}, \mathrm{Co}, \mathrm{Zn}$ and $\mathrm{Pb}[1]$. Growing concern on the presence of such pollutants in the aquatic environment has stimulated vigorous research activities in the development of specialized treatment technologies. This awareness along with the Egyptian government application of effluent standards has already forced many industries to implement appropriate treatment technologies. Initially, industries adopted simple physio-chemical treatment systems, but rapid degradation of the environment has forced governments to implement more stringent regulations for wastewater effluent and these standards have led to more advanced biological and membrane technologies. As water for industrial applications becomes less easily accessible, industry is looking for ways to recycle and reuse treated water.

Several techniques have been proposed to treat industrial wastewater to remove these heavy metals, such as precipitation, flotation, ion exchange, solvent extraction, adsorption, reverse osmosis, cementation, membrane processing and electrolytic methods, etc [2-5]. Among them, cementation is one of the oldest and simplest hydrometallurgical processes, which has been used as a means of extracting metals from solution [6-10]. Cementation is a metal replacement process by spontaneous redox reaction utilizing an electropositive sacrificing solid metal for the recovery of the electro-negative dissolved metal species originally present in wastewater. The advantage of cementation process includes its relatively simplicity, ease of control and possible recovery of valuable metals. However the consumption of sacrificing metal and the redox potential of the sacrificing metals are the main drawbacks of the process.

Cementation of copper is an electrochemical process in nature [6] which takes place through the galvanic cell: $\mathrm{Fe} /$ solution/Cu by the overall reaction:

$$
\mathrm{Cu}^{2+}+\mathrm{Fe} \rightarrow \mathrm{Cu}+\mathrm{Fe}^{2+}
$$

Besides, in acidic solutions $\mathrm{H}_{2}$ may evolve according to the reaction:

$$
\mathrm{Fe}+2 \mathrm{H}^{+} \rightarrow \mathrm{Fe}^{2+}+\mathrm{H}_{2}
$$

It is known that reaction (1) is much faster than reaction (2). However, reaction (2) is responsible for the consumption of excess iron. Stoichiometrically, $1 \mathrm{~kg}$ of copper is precipitated by $0.88 \mathrm{~kg}$ of iron. In practice, 1.2 to $2.6 \mathrm{~kg}$ of iron is consumed when $1 \mathrm{~kg}$ of copper is formed $[11,12]$. Copper was selected as the noble metal for two reasons: treatment and recycling of a toxic metal whose effects on the environment have been clearly proven and whose raw material cost has been sharply increasing in recent years. Iron has been chosen also as a sacrificial metal because of its relatively lower costs (approximately 10\% of the cost of copper [13]) and possible use or recovery of iron in hydrometallurgical processes

The application of electromagnetic field (EMF) for conducting fluids is a topic known as "Magneto hydrodynamics" (MHD) [14]. The idea of MHD is that magnetic fields can induce currents in a moving conductive fluid, which create forces on the fluid, and also change the magnetic field itself. The effect of magnetic field (MF) on electrochemical reactions has been the subject of many investigations [15]. The main interest in most of these investigations is directed towards the regions where the rate-determining step of the reaction is diffusion (or at least, region of mixed kinetics). . The application of the electromagnetic field was carried out to study the crystal growth under high magnetic field [16]. Another study found that high magnetic field has an effect on the anodic behavior of a ferromagnetic electrode [17], and on electro-deposition of CoFe alloys [18]. Mass transfer was found to increase during stirring a 
suspension of magnetic particles by the use of an alternating magnetic field [19]. Effect of MF on a cementation of copper was carried out by Gros et al [20]; they studied the recovery of copper by cementation in fixed and fluidized beds under transverse EMF. They found that the convective mass transfer coefficient was increased by a factor of 2.3 compared to cementation on fluidized bed without EMF.

The ions diffusion rate in cementation process can be enhanced by either moving the solution or moving the less noble metal $[20,21]$; however, studying the effect of moving ions inside the solution was not completely comprehended yet, especially in the presence of EMF. The aim of the present work is to illustrate the effect of utilization of uniform parallel electromagnetic field EMF on the elimination of copper from simulated industrial wastewater..

\section{Materials and methods}

Figure 1a shows a schematic diagram for the reaction cell, it consists of $1 \mathrm{dm}^{3}$ glass cylinder surrounded with copper coil. The iron cylinder $(0.02 \mathrm{~m}$ diameter $0.13 \mathrm{~m}$ height $)$ was immersed inside the reaction cell and connected to a variable speed motor (50 - $1500 \mathrm{rpm})$. Care was taken to avoid swirl motion of the cylinder. To simulate the industrial effluent, an aqueous solution of copper sulfate was prepared. All reagents used in this study were analytical grade and distilled water was used to prepare copper sulfate and sulfuric acid solutions $\left(\mathrm{CuSO}_{4} .5 \mathrm{H}_{2} \mathrm{O}, 99 \%\right.$ purity and $\mathrm{H}_{2} \mathrm{SO}_{4} 98 \%$ purity).

The experiments were carried out at ambient temperature $\left(25^{\circ} \mathrm{C}\right)$ for at most $90 \mathrm{~min}$. Before each run, a $0.5 \times 10^{-3} \mathrm{~m}^{3}$ of fresh copper sulfate solution was used together with new iron cylinder. Solution samples $\left(1 \mathrm{~cm}^{3}\right)$ were taken every 15 minutes during the experimental time for analysis. The samples were analyzed for detection of copper and iron ions by atomic absorption spectrophotometer (ELICO SL 176) at wave length of 324.7 and $248.3 \mathrm{~nm}$ for copper and iron respectively. The initial $\mathrm{pH}$ of copper sulfate solution was 2.5 and at the end of the cementation process was 3.9. The diffusivity of copper sulfate solution was obtained from literature [22].

The application of EMF was carried out by passing DC current through copper wire $(0.35 \mathrm{~mm}$ diameter) as solenoid around the reaction cell (800 turns). Consequently EMF was generated and its arbitrary direction was determined by right hand rule as shown in Fig.1(b). The current intensity and voltage were measured to calculate the power consumption.

\section{Results and discussion}

Figure 2 shows the percentage copper removal against time for the stationary iron cylinder either with EMF or without it. It was evident that application of EMF enhanced the percentage copper removal from the solution by 50\% compared to the experiment without EMF. Meanwhile, the percentage copper removal did not reach maximum value, this could be attributed to the existence of boundary layer that not only control the diffusion of both copper and iron ions but also decrease the ability of generated hydrogen bubbles from reaction (2) to detach from the surface of iron cylinder as shown in Fig 3.

Subsequently, the effect of parallel EMF was studied at different electromagnetic field intensities (EMFI) from 0 2462 A.T/m (Ampere. Turn/ meter), and at cylinder rotation speed of $900 \mathrm{rpm}$. The results illustrated in Fig. 4 proved that $57 \%$ additional removal of copper compared with experiment without EMF was attainable; also it is evident that $50 \%$ decrease in the cementation time is achieved by utilizing EMF. 
It is important to take into account the effect of rotation speed of iron cylinder in the presence of EMF; such effect will show the competitive action of both the thickness of boundary layer and the magnetic force. Fig. 5 shows the percentage copper removal against time at EMF of 2462 A.T/m and for different rotation speeds of iron cylinder.

The present study revealed that at lower stirring speeds, the cementation rate is slow due to the existence of boundary layer resistance around the iron cylinder, which resists the diffusion of copper ion from bulk of copper solution to iron cylinder. At high speed, the boundary layer thickness decreases and consequently the resistance to diffusion decreases, accordingly, the cementation rate was thus increased with increasing rotational speed. The results depicted in Fig 5 also speculated that the effect of decreasing the thickness of boundary layer is more dominant than the effect of EMF.

The effect of rotation speed on the rate of cementation can be used to determine mass transfer coefficient [23] which in turn, could be used to exemplify the positive effect of application of electromagnetic field. Many of the processes of metal removal from aqueous effluents that use solid-liquid systems obey a first-order kinetic law. The removal of copper can be evaluated by the following expression [24-26]:

$$
\frac{d C}{d t}=-k \frac{A C}{V}
$$

Where $C$ is the copper concentration $\left(\mathrm{mol} \mathrm{L}^{-1}\right)$ in solution at time $t(\mathrm{~s}), k$ is the mass-transfer coefficient, $\left(\mathrm{cm} \mathrm{s}^{-1}\right), A$ is exposed area $\left(\mathrm{cm}^{2}\right)$ of iron cylinder and $V$ is volume of solution $\left(\mathrm{cm}^{3}\right)$.

Assume that copper ion concentration is negligibly low at the iron/solution interface.

$$
-V \frac{d C}{d t}=k A C
$$

Equation (4) can be integrated to

$$
V \ln \frac{C o}{C}=k A t
$$

Where $C_{o}$ : is the initial concentration of copper.

Fig. 6 shows the relation between $\ln C_{d} / C$ and time for various rotation speeds of iron cylinder. It is evident, as confirmed by other researchers [21, 23, and 26], that the cementation reaction is a first-order reaction.

The mass transfer coefficient $\mathrm{k}$ was presented in Table 1. It can be noticed that up to rotation speed of $900 \mathrm{rpm}$, the application of EMF increases mass transfer coefficient by $126 \%$ since the EMF exerts two different effects: Firstly the generated magnetic field induces motion of paramagnetic ferrous ions inside the solution. Secondly, the magnetization of the iron cylinder influences the rate of deposition of copper ions. Nevertheless, at high rotation speed (1500 rpm) the mass transfer coefficient decreases. This decrease may be attributed to: (i) Vortex formation at high rpm that will reduce the active area of the rotating cylinder immersed in the solution. (ii) Vortex formation promotes the aeration as a result of increase in the interfacial area between air and solution. Consequently at high rotation speed, the application of magnetic field is impractical. 
Table 1: Mass transfer coefficient at different $\mathrm{EMF}$ and different $\mathrm{rpm},\left(\mathrm{C}_{0}=1000 \mathrm{ppm}\right.$, and $\mathrm{pH}=\mathbf{2 . 5}$ ).

\begin{tabular}{lll}
\hline $\begin{array}{l}\text { Cylinder rotation speed } \\
(\mathrm{rpm})\end{array}$ & $\begin{array}{l}\text { EMFI } \\
(\mathrm{A} . \mathrm{T} / \mathrm{m})\end{array}$ & $\begin{array}{l}\mathrm{k} \times 10^{3} \\
(\mathrm{~cm} / \mathrm{s})\end{array}$ \\
\hline \multirow{3}{*}{300} & 0 & 3.7 \\
& 615 & 5.50 \\
& 1231 & 4.89 \\
& 1846 & 5.50 \\
& 2462 & 7.34 \\
\hline \multirow{3}{*}{60} & 0 & 5.5 \\
& 615 & 12.85 \\
& 1231 & 7.95 \\
& 1846 & 11.63 \\
900 & 2462 & 14.69 \\
& 0 & 9.18 \\
& 615 & 10.40 \\
& 1231 & 12.24 \\
& 1846 & 14.07 \\
1500 & 2462 & 20.81 \\
\hline \multirow{3}{*}{} & 0 & 16.53 \\
& 615 & 14.58 \\
& 1231 & 15.54 \\
\hline
\end{tabular}

The mass transfer data with EMF were correlated by the following dimensionless equation:

$$
S h=2.3 R e^{0.95} S c^{0.33}
$$

where $S h$ is the Sherwood number $\left(S h=\frac{D k}{D_{A B}}, D\right.$ is the diameter of cylinder $(\mathrm{m})$ and $D_{A B}$ is the diffusion coefficient $\left.\left(\mathrm{m}^{2} / \mathrm{s}\right)\right), R e$ is the Reynolds number $\left(R e=\frac{\rho D N^{2}}{\mu}, \rho\right.$ is the density of solution $\left(\mathrm{kg} / \mathrm{m}^{3}\right), \mathrm{N}$ is the rotation speed of the iron cylinder $(\mathrm{r} / \mathrm{s})$, and $\mu$ is the viscosity of the solution $(\mathrm{kg} / \mathrm{ms})$ ), and $S c$ is the Schmidt number (. Although Equation (6) represents the dimensionless relation between mass transfer coefficient and the rotation speed, it does not account for the direct relation between the EMFI and the mass transfer coefficient, therefore the experimental data were used to predict mass transfer coefficient as function of rotational speed $(N)$, parallel electromagnetic field intensity $(H)$, and initial $\mathrm{Cu}$ concentration $\left(C_{0}\right)$. The correlation was obtained using DATAFIT software for curve fitting (nonlinear regression). For this case the initial copper concentration $\left(\mathrm{C}_{0}\right)$ was in the range of $200-1000 \mathrm{ppm}$, rotational speed range of $300-900 \mathrm{rpm}$ and parallel EMFI range of $615-2461 \mathrm{~A} . \mathrm{T} / \mathrm{m}$, the correlation that best fit the data was:

$$
k=\exp \left(a * N+b * C_{o}+d * H+f\right)
$$

Where: 
$a, b, d$, and $f$ are constants, $k$ is mass transfer coefficient, $\mathrm{m} / \mathrm{s}, H$ is parallel EMFI, A.T/m.

From the experimental data and by solving the equation the constants have been determined:

$$
k=\exp \left(1.44 * 10^{-3} * N+1.22 * 10^{-3} * C_{o}+4.05 * 10^{-4} * H-0.513\right)
$$

Figure 7 shows the relation between experimental and calculated values of mass transfer coefficient. It can be noticed that the empirical values of mass transfer coefficient are in agreement with the experimental values.

As has been already outlined, the main drawback of cementation process is the consumption of sacrificing metal (iron) and the redox potential of the sacrificing metals. The results in this study confirmed the reduction in the consumption of sacrificing metal by utilization of EMF. Such finding is evident from examination of Fig. 8 which shows the concentration of iron as function of time at different EMFI. It is noticeable that application of EMF decreases the concentration of iron ions in the solution. The EMF enhanced movement of charged ions by the Lorenz-force effect [18], as ferrous ions are paramagnetic, and these cause iron ions to move with magnetic moment parallel to the imposed magnetic field. This movement additionally decreases the boundary layer thickness, and increases the diffusion of copper ions to the surface of iron cylinder and consequently enhances the mass transfer of copper from bulk solution to the surface of iron cylinder [17].

In order to utilize magnetic field industrially, consideration of energy consumption of EMF is significant. As a case study, the data collected at $900 \mathrm{rpm}$ has been considered. It is important to take into account that the energy consumption is calculated as summation of both energy consumed for rotation and that consumed for generation of EMF. Table 2 shows the energy consumption. It is evident that the energy consumption is slightly affected by application of electromagnetic field as it was decreased by about $3 \%$ for parallel EMF. Such data indicate that with the same power consumption, copper recovery from wastewater can be attained faster with application of EMF.

Table 2: Energy consumption at different EMFI $\left(\mathrm{C}_{0}=1000 \mathrm{ppm}, \mathrm{N}=900 \mathrm{rpm}, \mathrm{pH}=2.5\right.$ and parallel direction).

\begin{tabular}{ll}
\hline \hline Magnetic field intensity (A.T/m) & Energy consumption $(\mathbf{k W . h / k g )}$ \\
\hline \hline 0 & 18.02 \\
615 & 19.36 \\
1230 & 17.50 \\
1846 & 18.01 \\
2461 & 19.69 \\
\hline \hline
\end{tabular}




\section{Conclusion}

This study confirms that the cementation process is diffusion controlled in presence of EMF. The influence of diffusion may be due to both MHD effect and the field gradient force. The mass transfer coefficient was doubled by application of EMF. The enhancement of copper recovery in application of electromagnetic field is due to induced motion of $\mathrm{Fe}^{+\mathrm{n}}$ in the solution. The data of mass transfer coefficient were correlated in dimensionless groups. The Power consumption per unit copper removal was slightly reduced in case of EMF implying that copper removal from wastewater can be attained faster with application of EMF.

\section{References}

[1] Babich, H., Devanas, M.A., Stotzky, G. The mediation of mutagenicity and clastogenicity of heavy metals by physicochemical factors, Env. Res., 37 (1985) 253-286.

[2] Lopez-Delgado A, Perez C, Lopez FA, Sorption of heavy metals on blast furnace sludge, Water Res, 32(1998) 989-96.

[3] Panizza Marco, Solisio Carlo b, Cerisola Giacomo, Electrochemical remediation of copper (II) from an industrial effluent Part II: three-dimensional foam electrodes, Resour. Conserv. Recycl.27 (1999) 299-307.

[4] Makhloufi L, Saidani B, Hammache H., Removal of lead from acidic aqueous solutions by cementation on iron", Water Res.; 34(2000)2517-24.

[5] Annamalai, V., Hiskey, J., Murr, L, The effects of kinetic variables on the structure of copper deposits cemented on pure aluminum discs: A scanning electron microscopic study, Hydrometallurgy, 3(1978) 163- 180.

[6] A.K. Biswas,W.G. Davenport, "Extractive Metallurgy of Copper", $4^{\text {th }}$ ed., Pergamon, New York, 265-289, 1979.

[7] F.A. Lopez, M.I. Martın, C. Perez, A. Lopez-Delgado, F.J. Alguacil, Removal of copper ions from aqueous solutions by a steel-making by-product, Water Res., 37(2003)3883-3890 .

[8] Annamalai, V., Hiskey, J., Murr, L., Effects of the source of chloride ion and surface corrosion patterns on the kinetics of the copper-aluminum cementation system , Hydrometallurgy, 3 (1978) 249- 263.

[9] Fisher, W., Fluidized cathode cementation of copper, Hydrometallurgy, 16 (1986) 5567.

[10] Karavasteva, M., The effect of certain surfactants on the cementation of copper by suspended zinc particles, Hydrometallurgy, 43(1996) 379- 385.

[11] A. Dib, L. Makhloufi, Cementation treatment of copper in wastewater: mass transfer in a fixed bed of iron spheres, Chem. Eng. Process., 43(2004) 1265-1273.

[12] Tadeusz Stefanowicz, Malgorzata Osifiska, Stefania Napieralska-Zagozda, Copper recovery by the cementation method, Hydrometallurgy; 47(1997) 69-90 .

[13] F. Gros, S. Baup , M. Aurousseau, Copper cementation on zinc and iron mixtures: Part 1: Results on rotating disc electrode, Hydrometallurgy, 106(2011) 127-133 . 
[14] R. Aogaki, K. Fueki, Application of a Magnetohydrodynamic Generator-Detector Electrode to Hydrodynamic Voltammetry, J. Electrochem. Soc., 131(1984) 1295-1300.

[15] V. C. Noninski, Magnetic field effect on copper electro-deposition in the Tafel potential region, Elecrrochimica Acta, 42( 1997)251-254.

[16] H. Mizuseki, K. Tanaka, K. Ohno and Y. Kawazoe, A new model for crystal growth under high magnetic field- effect of environment in diffusion limited aggregation, Sci. Rep. RITU (1997) 55-59.

[17] R. Sueptitz, J. Koza, M. Uhlemann, A. Gebert, L. Schultz, Magnetic field effect on the anodic behavior of a ferromagnetic electrode in acidic solutions, Electrochim. Acta, 54(2009) 2229-2233.

[18] Jakub Adam Koza, Margitta Uhlemann, Annett Gebert, Ludwig Schultz, The effect of magnetic fields on the electro-deposition of CoFe alloys, Electrochim. Acta 53(2008) 5344-5353.

[19] Reichert C., Hoell W.H., Franzreb M., Mass transfer enhancement in stirred suspensions of magnetic particles by the use of alternating magnetic fields, Powder Technol., 145(2004) 131-138.

[20] F. Gros, S. Baup, M. Aurousseau, Intensified recovery of copper in solution: Cementation onto iron in fixed or fluidized bed under electromagnetic field, Chem. Eng. Process., 47(2008) 295-302.

[21] Mervette El-Batouti, Removal of Copper by Cementation using Rotating iron cylinder, J. Colloid Interface Sci., 283(2005) 123-129.

[22] V. M. Lobo and J. L. Quaresma, "Electrolyte Solutions: Literature Data on Thermodynamics and Transport Properties", Vol. 2, Coimbra, Portugal 1981.

[23] Dimitrova SV. "Metal sorption on blast furnace slag", Water Res.,30(1996) 228-232.

[24] G. Power, I.M. Richie, A contribution to the theory of cementation (metal displacement) reactions", Aust. J. Chem. 29 (1976) 699-709.

[25] Mamdouh M. Nassar, Olfat A. Fadali and G. H. Sedahmed, Effect of Drag Reducing Polymer on the Rate of Cementation of Copper from dilute Solutions on Rotating Zinc Cylinder, Metalkund, (1989) 60-62.

[26] Annamalai, V., Murr, L., Influence of deposit morphology on the kinetics of copper cementation on pure iron, Hydrometallurgy, 4(1979) 57- 82. 


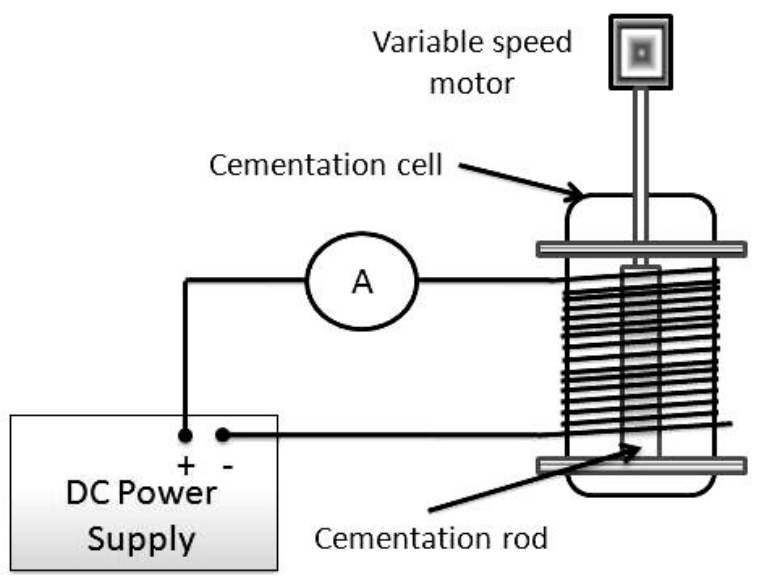

(a)

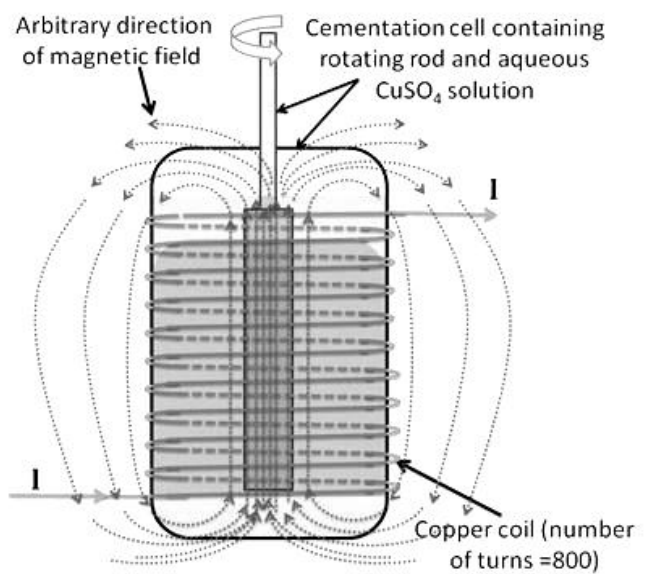

(b)

Fig 1: (a) Setup of cementation cell (b) magnetic field to cylinder configuration

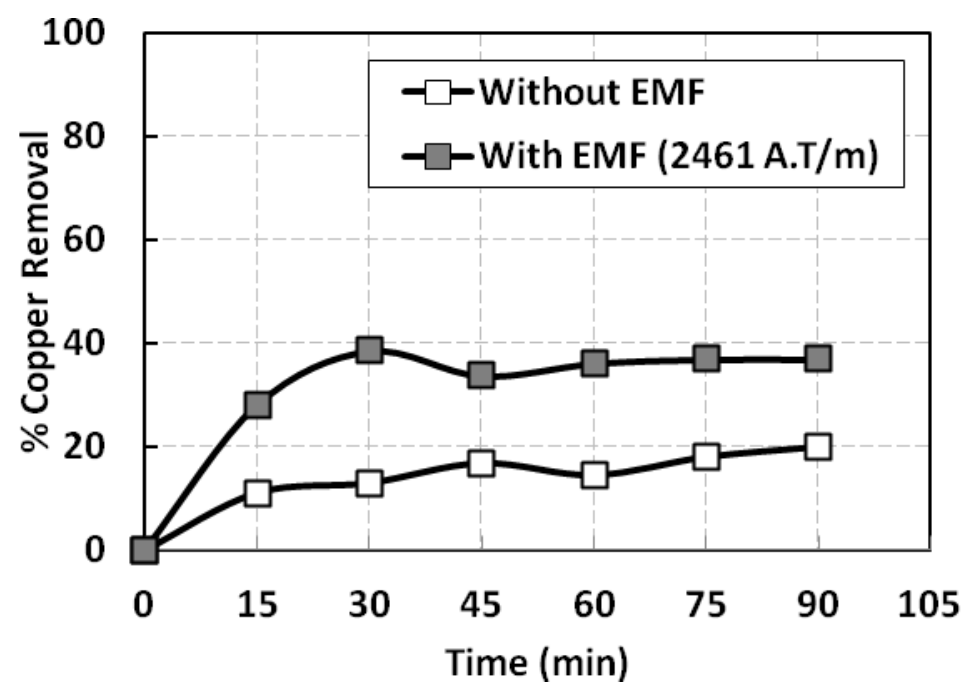

Fig. 2: Percentage $\mathrm{Cu}$ removal vs. time with and without $\mathrm{EMF}$. $(\mathrm{rpm}=0$, and $\mathrm{pH}=2.5)$. 

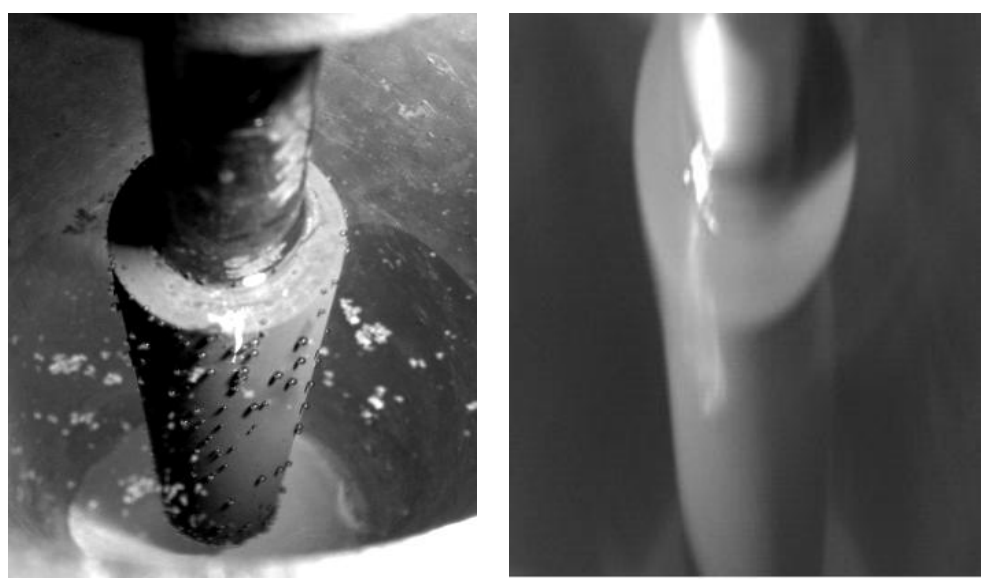

Fig. 3: Iron cylinder immersed in copper sulfate solution, left: stationary iron cylinder with hydrogen bubbles attached to the surface, right: rotating iron cylinder.

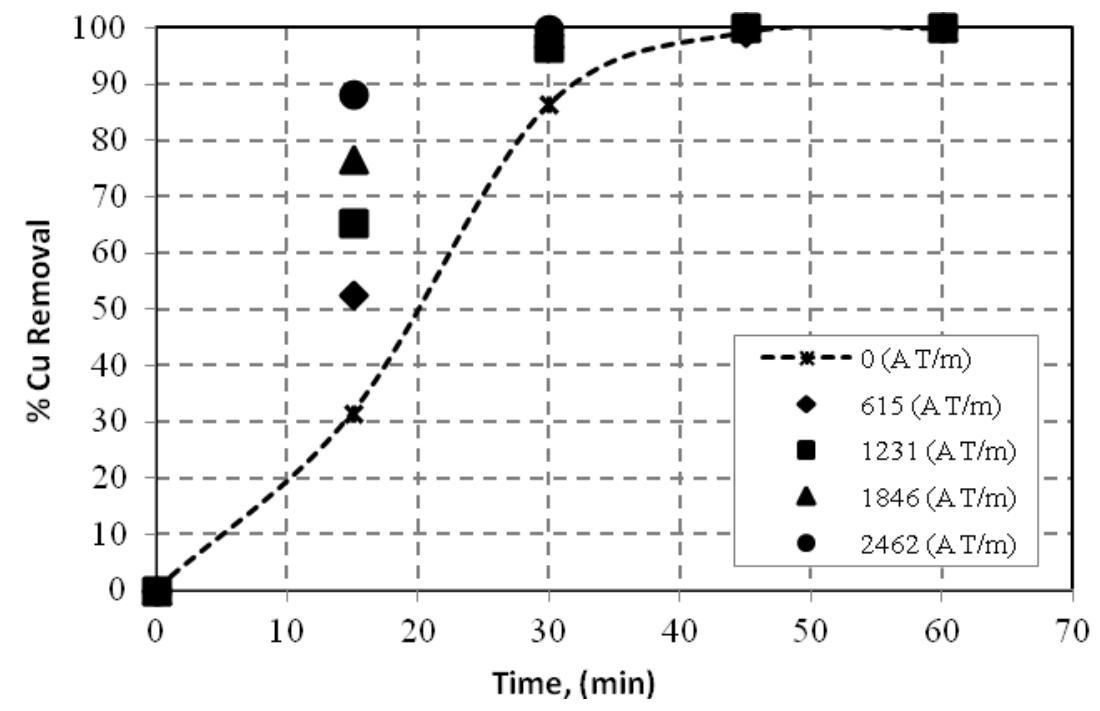

Fig.4: Percentage $\mathrm{Cu}$ removal vs time with different EMF. $(\mathrm{rpm}=900$, and $\mathrm{pH}=2.5)$. 


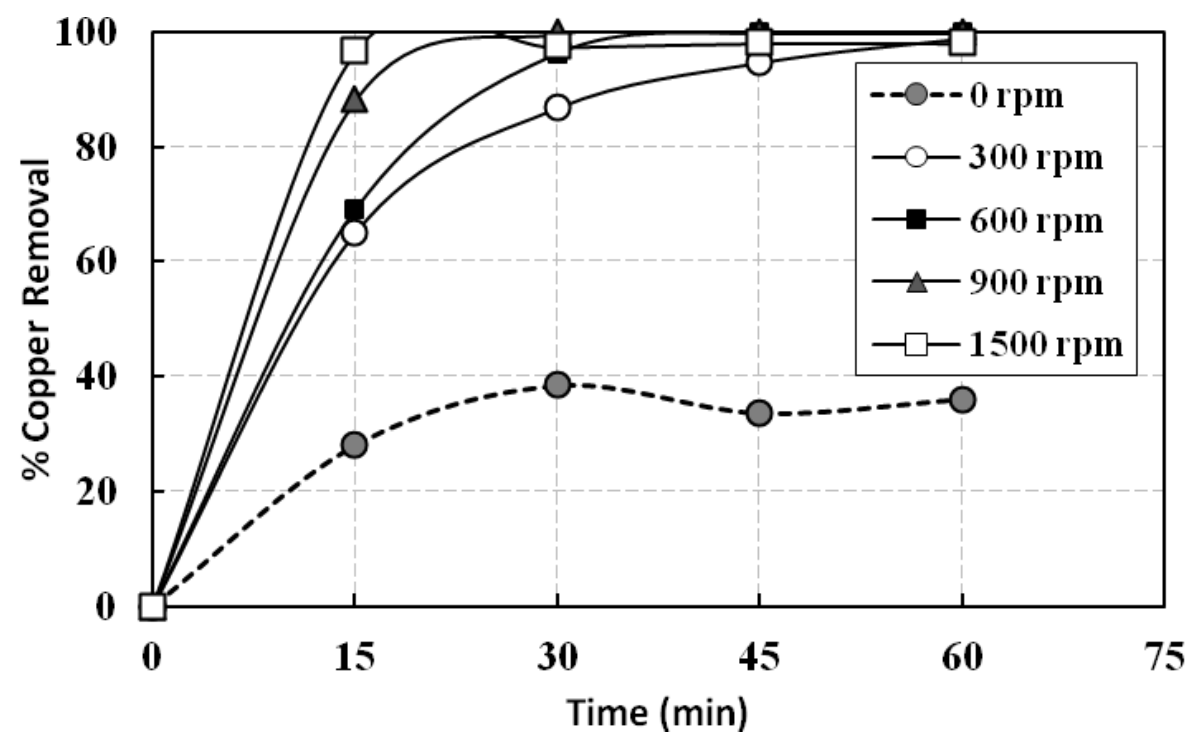

Fig.5: Percentage $\mathrm{Cu}$ removal vs time with different rpm $(\mathrm{EMFI}=2461 \mathrm{~A} \mathrm{~T} / \mathrm{m}$, and $\mathrm{pH}=2.5)$.

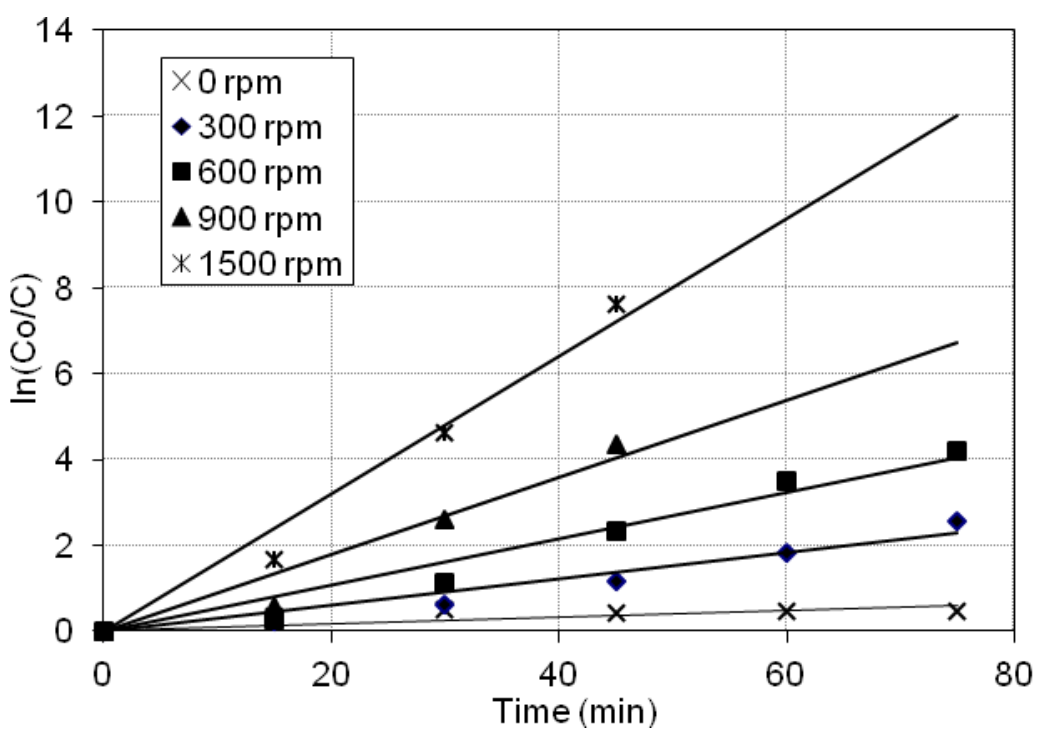

Fig. 6: $\ln (\mathrm{Co} / \mathrm{C})$ vs. time at different rotational speeds at $\left(\mathrm{pH}=2.5, \mathrm{C}_{0}=1000 \mathrm{ppm}\right.$, and $\left.\mathrm{EMFI}=2462 \mathrm{~A} \mathrm{~T} / \mathrm{m}\right)$ 


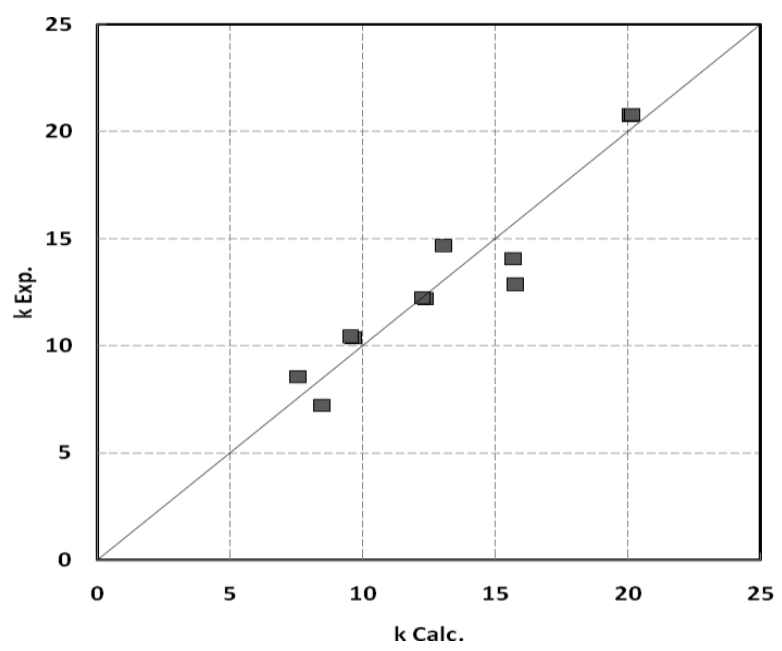

Fig. 7: Forty five degree line between the experimental and calculated mass transfer coefficients

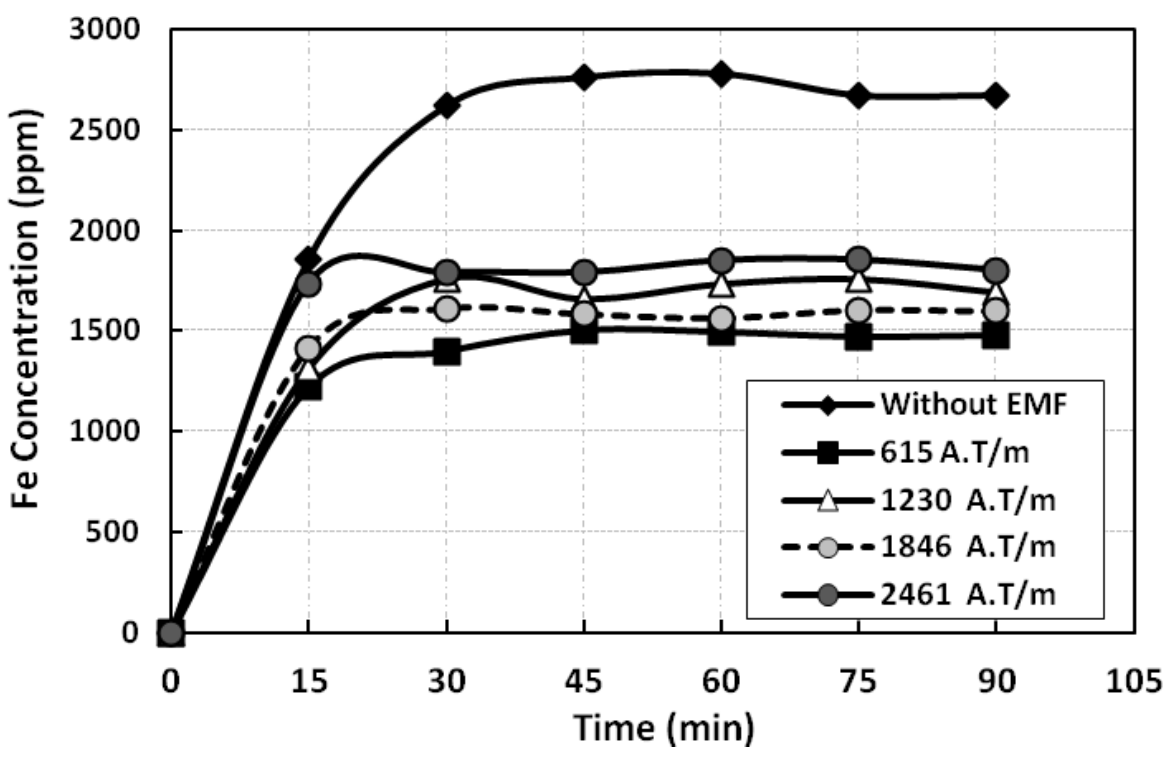

Fig.8: Concentration of Fe ion vs time at different EMFI $\left(\mathrm{rpm}=900, \mathrm{C}_{0}=1000 \mathrm{ppm}\right.$, and $\left.\mathrm{pH}=\mathbf{2 . 5}\right)$. 